\title{
Proteolysis and Phenylalanine Hydroxylation in Response to Parenteral Nutrition in Extremely Premature and Normal Newborns
}

\author{
Scott C. Denne, Cheryl A. Karn, Julie A. Ahlrichs, Asuncion R. Dorotheo, Junying Wang, and Edward A. Liechty \\ Department of Pediatrics, Section of Neonatal-Perinatal Medicine, Indiana University School of Medicine, Indianapolis, Indiana 46202
}

\begin{abstract}
To determine to what extent intravenous nutrition can reduce proteolysis in very immature and normal newborns, and to assess the capacity of preterm and normal newborns to convert phenylalanine to tyrosine, phenylalanine and leucine kinetics were measured under basal conditions and during parenteral nutrition in clinically stable, extremely premature ( $\sim 26 \mathrm{wk}$ of gestation) infants and in normal term newborns. In response to parenteral nutrition, there was significantly less suppression $(P<0.001)$ of endogenous leucine and phenylalanine rate of appearance in extremely premature infants compared with term infants. Phenylalanine utilization for protein synthesis during parenteral nutrition increased significantly $(P<0.01)$ and by the same magnitude $(\sim 15 \%)$ in both extremely premature and term infants. Phenylalanine was converted to tyrosine at substantial rates in both extremely premature and term infants; however, this conversion rate was significantly higher $(P<0.05)$ in extremely premature infants during both the basal and parenteral nutrition periods. These data provide clear evidence that there is no immaturity in the phenylalanine hydroxylation pathway. Furthermore, although parenteral nutrition appears to produce similar increases in protein synthesis in extremely premature and term infants, proteolysis is suppressed much less in extremely premature newborns. The factors responsible for this apparent resistance to suppression of proteolysis in the very immature newborn remain to be elucidated. (J. Clin. Invest. 1996. 97:746-754.) Key words: stable isotope tracers - protein turnover • protein synthesis • leucine • phenylalanine
\end{abstract}

\section{Introduction}

Immature individuals are characterized by high rates of protein turnover, with the highest rates occurring in the most immature (1-4). These high rates of protein synthesis and proteolysis may be necessary to provide continuous amino acid

Address correspondence to Scott C. Denne, M.D., Indiana University School of Medicine, Department of Pediatrics, Riley Hospital for Children, 702 Barnhill Drive RR 208, Indianapolis, IN 46202-5210. Phone: 317-274-4902; FAX: 317-274-2065; E-mail: sdenne@indyvax.iupui.edu

Received for publication 7 August 1995 and accepted in revised form 13 November 1995.

J. Clin. Invest.

(c) The American Society for Clinical Investigation, Inc.

0021-9738/96/02/0746/09 \$2.00

Volume 97, Number 3, February 1996, 746-754 availability for remodeling and potential growth. To maintain and accrete body protein, nutrient intake must affect increases in protein synthesis, reductions in proteolysis, or both. Reducing proteolysis in response to nutrient intake is an important mechanism whereby whole body protein is maintained in adults (5-8). However, it is unclear at present to what extent newborns are able to reduce proteolysis in response to nutrient intake. This is an important issue because the preservation and accretion of whole body protein, although a primary clinical goal, can be difficult to achieve in premature infants.

We have evaluated recently the effect of intravenous glucose infusions on whole body proteolysis in both normal and extremely premature $(\sim 26$ wk of gestation) infants $(4,9)$. In contrast to the suppression of proteolysis observed in adults (5), glucose infusions (with a concomitant increase in insulin concentrations) affected no changes in whole body proteolysis in either extremely premature or term newborns $(4,9)$. Moreover, in term infants, intravenous lipid, alone or in combination with glucose, also did not reduce proteolysis below basal values (9). We therefore questioned whether a complete parenteral nutrition solution (containing glucose, lipid, and amino acids), delivered in quantities sufficient to support growth, could successfully suppress proteolysis and thereby spare endogenous protein stores in either normal or very immature human newborns. We postulated that proteolysis would be least responsive to nutrient intake in the most immature. To evaluate this hypothesis, we measured the endogenous rates of appearance of the essential amino acids leucine and phenylalanine (reflecting proteolysis) in response to parenteral nutrition in clinically stable, extremely premature ( $\sim 26$ wk of gestation) infants and in normal full term infants within the first few days of life.

In addition to assessing the endogenous release of essential amino acids, examining the utilization of specific amino acids in newborns is also important. In particular, determining rates of phenylalanine hydroxylation to tyrosine in normal and premature newborns is especially relevant. Tyrosine is an essential amino acid if active phenylalanine hydroxylation does not occur; at present, tyrosine is widely considered an essential amino acid in premature infants (10-12), although some conflicting data exists $(13,14)$. Determining whether or not tyrosine is an essential amino acid in prematurity is more than of academic interest because there is little or no tyrosine in most commercially available amino acid solutions, and thus tyrosine for net protein accretion during parenteral nutrition can only be made available by phenylalanine hydroxylation. We hypothesized that the capacity to convert phenylalanine to tyrosine in the basal state and in response to exogenous phenylalanine supply during intravenous nutrition would be reduced in the very immature. To test this hypothesis, we quantified phenylalanine hydroxylation and tyrosine rate of appearance in extremely premature and normal term newborns under basal conditions and during parenteral nutrition. 


\begin{tabular}{|c|c|c|c|c|c|c|c|c|c|}
\hline \multirow[b]{2}{*}{ Subject } & \multirow[b]{2}{*}{ Sex } & \multirow[b]{2}{*}{ Gestational age } & \multirow[b]{2}{*}{ Birth weight } & \multirow[b]{2}{*}{ Study weight } & \multirow[b]{2}{*}{ Age at study } & \multicolumn{4}{|c|}{ Ventilator support during study } \\
\hline & & & & & & PIP & PEEP & Rate & $\mathrm{FiO}_{2}$ \\
\hline & & $w k$ & $\mathrm{~kg}$ & $\mathrm{~kg}$ & $d$ & $\mathrm{~cm} \mathrm{H}_{2} \mathrm{O}$ & $\mathrm{cm} \mathrm{H}_{2} \mathrm{O}$ & & \\
\hline 1 & $\mathrm{M}$ & 25 & 0.684 & 0.680 & 2 & 22 & 4 & 45 & 0.21 \\
\hline 2 & $\mathrm{~F}$ & 24.5 & 0.713 & 0.710 & 2 & 14 & 4 & 22 & 0.21 \\
\hline 3 & $\mathrm{~F}$ & 24.5 & 0.825 & 0.790 & 2 & 18 & 4 & 25 & $0.21-0.25$ \\
\hline 4 & $\mathrm{M}$ & 25 & 1.00 & 0.865 & 3 & 14 & 4 & 12 & 0.21 \\
\hline 5 & $\mathrm{M}$ & 27 & 0.975 & 0.832 & 3 & 14 & 4 & 12 & 0.21 \\
\hline 6 & $\mathrm{M}$ & 26 & 0.853 & 0.901 & 1 & 16 & 4 & 16 & $0.21-0.28$ \\
\hline 7 & $\mathrm{M}$ & 30 & 1.12 & 1.16 & 5 & 18 & 4 & 30 & $0.21-0.23$ \\
\hline 8 & $\mathrm{~F}$ & 23.5 & 0.643 & 0.490 & 4 & 16 & 4 & 24 & 0.21 \\
\hline Mean & & 25.7 & 0.852 & 0.804 & 2.8 & & & & \\
\hline SEM & & 0.7 & 0.1 & 0.1 & 0.5 & & & & \\
\hline 9 & $\mathrm{~F}$ & 40 & 3.50 & 3.53 & 1 & & & & \\
\hline 10 & $\mathrm{~F}$ & 40 & 3.54 & 3.31 & 2 & & & & \\
\hline 11 & $\mathrm{M}$ & 39 & 3.06 & 2.94 & 2 & & & & \\
\hline 12 & $\mathrm{M}$ & 40 & 4.04 & 3.72 & 3 & & & & \\
\hline 13 & $\mathrm{~F}$ & 39 & 2.81 & 2.77 & 1 & & & & \\
\hline 14 & $\mathrm{~F}$ & 39 & 3.34 & 3.13 & 5 & & & & \\
\hline 15 & $\mathrm{M}$ & 40 & 3.45 & 3.17 & 2 & & & & \\
\hline 16 & $\mathrm{~F}$ & 39 & 2.90 & 2.88 & 2 & & & & \\
\hline 17 & $\mathrm{~F}$ & 40 & 3.64 & 3.55 & 3 & & & & \\
\hline 18 & $\mathrm{~F}$ & 39 & 3.10 & 3.06 & 1 & & & & \\
\hline Mean & & 39.5 & 3.34 & 3.21 & 2.2 & & & & \\
\hline SEM & & 0.2 & 0.1 & 0.1 & 0.4 & & & & \\
\hline
\end{tabular}

$P I P$, peak inspiratory pressure; $P E E P$, positive end expiratory pressure; $\mathrm{FiO}_{2}$, fraction of inspired oxygen.

\section{Methods}

\section{Subjects}

Studies were approved by the Institutional Review Board of Indiana University, and written informed consent was obtained from the parents. Study subjects included 8 clinically stable extremely premature infants ( $\sim 26$ wk of gestation) and 10 normal full term newborns. The clinical characteristics of the study subjects are summarized in Table I. All infants were appropriate for gestational age, had no congenital anomalies, and were studied at $\leq 5 \mathrm{~d}$ of age. Term infants were clinically normal as determined by physical exam, had uncomplicated postnatal courses (no birth asphyxia, no supplemental oxygen, no antibiotics), and were tolerating enteral feedings well. Infants in the extremely premature $(\mathrm{EP})^{1}$ group were stable on low ventilator settings and there were no significant changes in these settings for the $24 \mathrm{~h}$ before or after the study. Six of the eight EP infants had previously received a course of surfactant replacement therapy based on clinical and radiographic evidence of respiratory distress syndrome; the remaining two had no evidence of surfactant deficiency. None of the EP subjects had received inotropic support or enteral or parenteral feedings before study. Intravenous glucose was being provided at a rate of $6.67 \pm 3.46 \mathrm{mg} / \mathrm{kg} / \mathrm{min}$ for the $24 \mathrm{~h}$ before the study as is typical clinical practice in EP infants. Each EP infant also had an umbilical arterial catheter and venous access in place before the study.

\section{Protocol}

Term infants were studied 3-4 h after receiving a normal feeding. A 22-gauge catheter was placed in a superficial vein for the purpose of

1. Abbreviations used in this paper: EP, extremely premature; KIC, ketoisocaproic acid; PN, parenteral nutrition; Ra, rate of appearance. drawing blood and a baseline blood sample was obtained. A separate catheter was placed in the opposite extremity and a priming dose of tracers (in normal saline), representing $90 \mathrm{~min}$ of infusion, was administered over $5 \mathrm{~min}$. Thereafter, constant infusions of $\left[1-{ }^{13} \mathrm{C}\right]$ leucine $(7 \mu \mathrm{mol} / \mathrm{kg} / \mathrm{h}),\left[\mathrm{d}_{5}\right]$ phenylalanine $(2.5 \mu \mathrm{mol} / \mathrm{kg} / \mathrm{h})$, and $\left[\mathrm{d}_{2}\right]$ tyrosine $(1.4 \mu \mathrm{mol} / \mathrm{kg} / \mathrm{h})$ dissolved in normal saline were delivered through the second venous catheter via an infusion pump (Harvard Apparatus, Inc., South Natick, MA). Blood samples were obtained at $120,140,160$, and $180 \mathrm{~min}$. At the end of $180 \mathrm{~min}$ of study, term newborns had been fasting $6.8 \pm 0.6 \mathrm{~h}$. Blood was immediately analyzed for plasma glucose concentration, and the remainder of the sample was then frozen at $-70^{\circ} \mathrm{C}$ for later analysis.

After the 180-min sample, an intravenous solution of glucose $(8$ $\mathrm{mg} / \mathrm{kg} / \mathrm{min}$ ), lipid (165 mg/kg/h) (LiposynIII 10\%, Abbott Laboratories, North Chicago, IL), and amino acids $(105 \mathrm{mg} / \mathrm{kg} / \mathrm{h}$ ) (AminosynPF; Abbott Laboratories) was begun and continued for the remaining $2.5 \mathrm{~h}$ of the study. The amino acid solution provided $95 \mu \mathrm{mol} / \mathrm{kg} / \mathrm{h}$ of leucine, $27 \mu \mathrm{mol} / \mathrm{kg} / \mathrm{h}$ of phenylalanine, and $2.5 \mu \mathrm{mol} / \mathrm{kg} / \mathrm{h}$ of tyrosine. If this infusion were to continue over a 24 -h period, it would provide $90 \mathrm{kcal} / \mathrm{kg}, 2.5 \mathrm{grams} / \mathrm{kg}$ of protein, $4 \mathrm{grams} / \mathrm{kg}$ of lipid, and 11.5 grams $/ \mathrm{kg}$ of glucose. Blood samples were then obtained at 270 , 290, 310, and $330 \mathrm{~min}$, analyzed for plasma glucose, and frozen for later analysis.

The EP infants had umbilical artery catheter fluids changed to normal saline at the beginning of the study and a baseline blood sample was obtained. A priming dose of tracers, also in normal saline and representing $90 \mathrm{~min}$ of infusion, was administered over $5 \mathrm{~min}$ through the venous catheter. A constant infusion of $\left[1{ }^{13} \mathrm{C}\right]$ leucine $(10 \mu \mathrm{mol} /$ $\mathrm{kg} / \mathrm{h}),\left[\mathrm{d}_{5}\right]$ phenylalanine $(4 \mu \mathrm{mol} / \mathrm{kg} / \mathrm{h})$, and $\left[\mathrm{d}_{2}\right]$ tyrosine $(2 \mu \mathrm{mol} / \mathrm{kg} /$ h) was then begun and continued throughout the study period. The rate of tracer infusion in EP infants was slightly higher than those used in term infants in order to achieve plasma enrichments in the 
same range for both groups. The tracers were dissolved in unlabeled $\mathrm{D}_{10} \mathrm{~W}$ to provide a calculated rate of $6 \mathrm{mg} / \mathrm{kg} / \mathrm{min}$ glucose. This allowed the total amount of fluid each infant received to remain unchanged from the prestudy rate. Furthermore, this rate of glucose administration maintained constant glucose concentrations, prevented hypoglycemia, and was designed to achieve glucose and insulin concentrations in EP infants similar to those in fasting term newborns.

Blood samples were obtained from the EP infants at 120,135, and $150 \mathrm{~min}$. After the $150 \mathrm{~min}$ sample, intravenous nutrition was begun delivering glucose, protein, and lipid at rates identical to the term infants and further blood samples obtained at 270, 285, and $300 \mathrm{~min}$. All blood samples were immediately analyzed for plasma glucose concentration and then frozen for later analysis. Syringes containing infusates in both groups were weighed before and after infusion to quantitate volume actually delivered and each infusate was analyzed for the concentration of leucine, phenylalanine, and tyrosine.

\section{Analytical methods}

Plasma enrichments. The plasma enrichments of leucine, phenylalanine, tyrosine and $\alpha$-ketoisocaproic acid (KIC) were determined by electron impact ionization and selected ion monitoring on a gas chromatograph mass spectrometer (model 5970; Hewlett-Packard Co., Palo Alto, CA). The enrichments of plasma leucine, phenylalanine, and tyrosine were determined by monitoring ions 302 and 303 (leucine), 234 and 239 (phenylalanine), and 466, 468, and 470 (tyrosine) after derivatization to the tertiary butyldimethylsilyl derivatives ( 9 , 15). The plasma enrichment of KIC was determined after derivatization to the $O$-trimethylsilylquinoxalinol by monitoring ions 232 and $233(9,16)$. The final value for all determinations was corrected using an enrichment calibration curve. The mean enrichment values of three samples (EP infants) or four samples (term infants) taken during enrichment plateau in each subject were used for further analysis.

Substrate and hormone concentrations. Plasma glucose concentrations were determined by the glucose oxidase method (Yellow Springs Instruments, Yellow Springs, $\mathrm{OH}$ ) on all samples obtained; the coefficient of variation was $<8 \%$ in both groups during the basal and parenteral nutrition (PN) periods. The average glucose concentration during each of the two periods is reported. Plasma concentrations of amino acids were determined on a Beckman 6300 Amino Acid Analyzer (Beckman Instruments, Inc., Fullerton, CA). The average of four determinations during the basal state and four determinations during $\mathrm{PN}$ is reported for the term infant group. The coefficient of variation was $<7 \%$ during the basal and PN periods for leucine, phenylalanine and tyrosine concentrations. Because only a limited amount of blood was obtained from EP infants, amino acid concentrations were measured on only one sample during each of the two periods. For both groups, plasma insulin concentrations were measured on one sample during each of the two periods by double antibody radioimmunoassay.

\section{Calculations}

Plasma enrichments of leucine, phenylalanine, and tyrosine were used to calculate the rates of appearance of these amino acids. In addition, leucine rate of appearance was also calculated based upon the enrichment of KIC, the intracellular transamination product of leucine. This precursor was measured because its plasma enrichment has been shown to closely approximate intracellular leucine enrichment (17).

The total rates of appearance of leucine, phenylalanine, and tyrosine were each calculated by measuring tracer dilution at steady state as modified for stable isotopic tracers $(18,19)$ :

$R a=\left(\frac{100}{E P}-1\right) \times I ;$

where $R a$ is the rate of appearance of the amino acid, $E P$ is the steady state enrichment of the specific isotope, and I is the rate of tracer infusion.

Endogenous Ra of leucine and phenylalanine (reflecting proteol- ysis) were calculated by subtracting the rate of exogenous administration of unlabeled leucine or phenylalanine from their measured total $\mathrm{Ra}(7,8)$. Endogenous $\mathrm{Ra}$ of leucine was calculated using the unlabeled leucine infusion and the total leucine Ra based on both KIC enrichment and leucine enrichment.

Phenylalanine hydroxylation to tyrosine $\left(Q_{\mathrm{PT}}\right)$ was calculated as follows (20):

$Q_{\mathrm{PT}}=T y r R a \times \frac{{ }^{2} \mathrm{H}_{4} T y r}{{ }^{2} \mathrm{H}_{5} \text { Phe }} \times \frac{P h e R a}{\mathrm{I}_{\mathrm{Phe}}+\text { Phe Ra }} ;$

where ${ }^{2} \mathrm{H}_{4} T y r$ and ${ }^{2} \mathrm{H}_{5}$ Phe are the isotopic enrichments of the respective tracers in plasma, and $I_{\text {Phe }}$ is the infusion rate of tracer phenylalanine $(\mu \mathrm{mol} / \mathrm{kg} / \mathrm{h})$. The expression

$\frac{\text { Phe Ra }}{I_{\text {Phe }}+\text { Phe Ra }}$

corrects for the contribution of the phenylalanine tracer infusion to $Q_{\mathrm{PT}}$.

Phenylalanine utilization for protein synthesis was calculated by subtracting $Q_{\mathrm{PT}}$ from Phe $\mathrm{Ra}$, since phenylalanine is irreversibly lost either by its degradation pathway via its conversion into tyrosine, or by incorporation of protein $(20,21)$.

\section{Statistics}

All results are reported as the mean \pm SEM. Comparisons within groups were made using the paired $t$ test, and between groups using ANOVA.

\section{Results}

Glucose, insulin, and amino acid concentrations. Plasma glucose and insulin concentrations are shown in Table II. Glucose concentrations were similar in the EP and term infants in both the basal period and during PN. As expected, glucose concentrations increased significantly from basal values in both groups of infants. Similarly, insulin concentrations also significantly increased during PN in both groups. In the basal period, insulin concentrations were low in both groups, but the small $(\sim 2 \mu \mathrm{U} / \mathrm{ml})$ difference in the concentrations was statistically significant. However, there was no difference in the insulin concentrations between EP and term infants during PN.

Plasma amino acid concentrations measured during the studies are shown in Table III. As expected, the plasma concentrations of many amino acids, including all of the essential amino acids, increased during PN in both groups of infants. However, it is worth noting that tyrosine concentrations did not significantly change from basal values in either group; again this was not unexpected in view of the extremely small amount of tyrosine supplied in the amino acid solution used.

Table II. Glucose and Insulin Concentrations in the Basal Period and during $P N$

\begin{tabular}{lccccc}
\hline & \multicolumn{3}{c}{ EP } & & \multicolumn{2}{c}{ Term } \\
\cline { 2 - 3 } \cline { 5 - 6 } & Basal & PN & & Basal & PN \\
\hline $\begin{array}{c}\text { Glucose } \\
(\mathrm{mg} / \mathrm{dl})\end{array}$ & $81 \pm 6$ & $114 \pm 8^{*}$ & & $74 \pm 13$ & $108 \pm 8^{*}$ \\
$\begin{array}{c}\text { Insulin } \\
(\mu \mathrm{U} / \mathrm{ml})\end{array}$ & $5 \pm 1^{\ddagger}$ & $17 \pm 5^{*}$ & $3 \pm 1$ & $24 \pm 5^{*}$ \\
& & & & \\
\end{tabular}

${ }^{*} P<0.01$ Basal vs. $\mathrm{PN} ;{ }^{*} P<0.01 \mathrm{EP}$ vs. Term. 
Table III. Amino Acid Concentrations in the Basal Period and during $P N$

\begin{tabular}{|c|c|c|c|c|}
\hline \multirow[b]{2}{*}{ Amino acid } & \multicolumn{2}{|c|}{ EP } & \multicolumn{2}{|c|}{ Term } \\
\hline & Basal & $\mathrm{PN}$ & Basal & $\mathrm{PN}$ \\
\hline Phe & $109 \pm 7$ & $153 \pm 10 *$ & $58 \pm 4$ & $74 \pm 3 *$ \\
\hline Leu & $96 \pm 11$ & $191 \pm 15^{* \ddagger}$ & $76 \pm 5$ & $125 \pm 14 *$ \\
\hline Ile & $31 \pm 4$ & $91 \pm 8^{*}$ & $43 \pm 6$ & $88 \pm 7 *$ \\
\hline Val & $161 \pm 16^{\ddagger}$ & $245 \pm 13^{* \neq}$ & $101 \pm 16$ & $143 \pm 23 *$ \\
\hline Thr & $130 \pm 15$ & $193 \pm 21 *$ & $135 \pm 14$ & $158 \pm 14 *$ \\
\hline Lys & $143 \pm 16$ & $198 \pm 11^{* \neq}$ & $120 \pm 11$ & $155 \pm 13 *$ \\
\hline $\operatorname{Trp}$ & $89 \pm 22$ & $81 \pm 11$ & $71 \pm 10$ & $84 \pm 13 *$ \\
\hline Met & $30 \pm 5$ & $39 \pm 5$ & $32 \pm 3$ & $43 \pm 3 *$ \\
\hline His & $90 \pm 8$ & $101 \pm 5$ & $72 \pm 7$ & $88 \pm 6^{*}$ \\
\hline Tyr & $193 \pm 45^{\ddagger}$ & $216 \pm 47^{\ddagger}$ & $75 \pm 9$ & $79 \pm 8$ \\
\hline Cys & $28 \pm 4^{\ddagger}$ & $29 \pm 4^{\ddagger}$ & $18 \pm 3$ & $18 \pm 3$ \\
\hline Pro & $123 \pm 19$ & $260 \pm 34 *$ & $155 \pm 13$ & $227 \pm 9 *$ \\
\hline Ser & $134 \pm 23$ & $175 \pm 17 *$ & $158 \pm 15$ & $175 \pm 12$ \\
\hline Arg & $42 \pm 6$ & $95 \pm 5^{*}$ & $62 \pm 10$ & $118 \pm 10^{*}$ \\
\hline Ala & $124 \pm 21^{\ddagger}$ & $233 \pm 32 *$ & $199 \pm 14$ & $257 \pm 19 *$ \\
\hline Gly & $217 \pm 25$ & $269 \pm 21 *$ & $286 \pm 27$ & $306 \pm 21$ \\
\hline Asp & $9 \pm 1$ & $17 \pm 2 * \ddagger$ & $10 \pm 1$ & $12 \pm 1$ \\
\hline Asn & $50 \pm 9$ & $48 \pm 8^{\ddagger}$ & $40 \pm 3$ & $30 \pm 3$ \\
\hline Glu & $35 \pm 5^{\ddagger}$ & $62 \pm 6^{* \ddagger}$ & $135 \pm 24$ & $123 \pm 14$ \\
\hline Gln & $374 \pm 69^{\ddagger}$ & $485 \pm 57 *$ & $529 \pm 28$ & $564 \pm 37$ \\
\hline
\end{tabular}

All values are presented in $\mu \mathrm{mol} /$ liter. $* P<0.01$ Basal vs. $\mathrm{PN} ;{ }^{*} P<0.05$ EP vs. Term.
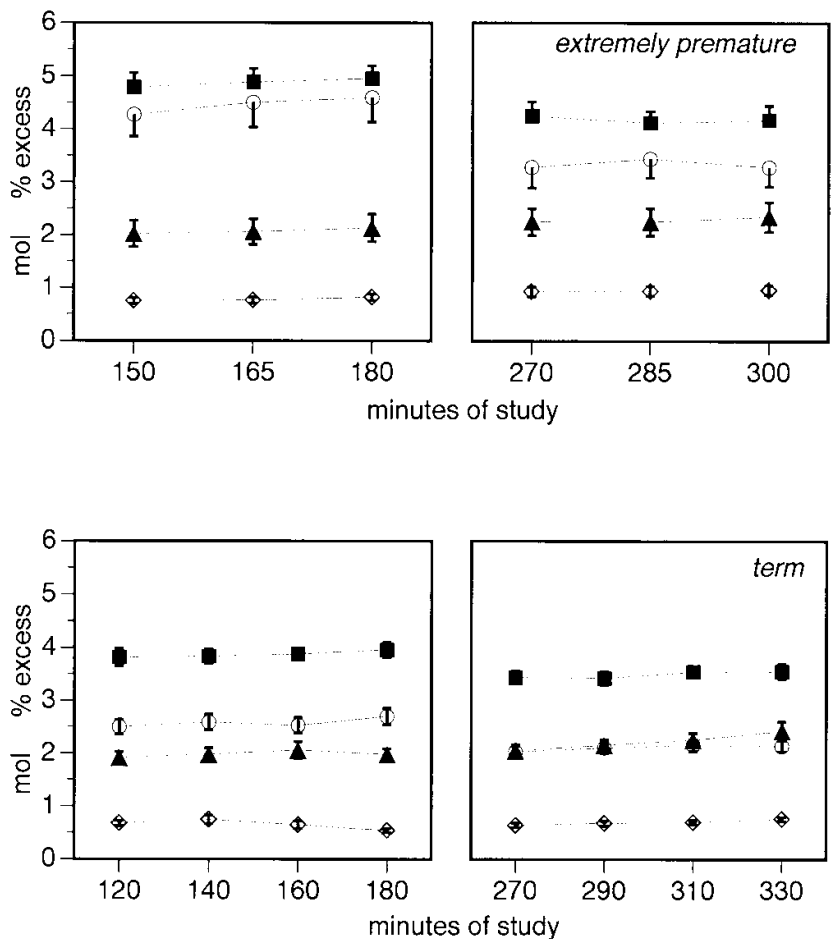

Figure 1. Tracer enrichments measured during the studies. The box on the left corresponds to the basal period and the box on the right corresponds to the PN period. Filled boxes, $\mathrm{d}_{5}$ PHE; open circles, ${ }^{13} \mathrm{C}$ $\mathrm{KIC}$; filled triangles, $\mathrm{d}_{2} \mathrm{Tyr}$; open diamonds, $\mathrm{d}_{4} \mathrm{Tyr}$.
Table IV. Leucine, Phenylalanine, and Tyrosine Ra in the Basal Period and during PN

\begin{tabular}{lccccc}
\hline & \multicolumn{2}{c}{ EP } & & \multicolumn{2}{c}{ Term } \\
\cline { 2 - 3 } \cline { 5 - 6 } \cline { 5 - 6 } & Basal & PN & & Basal & PN \\
\hline Leucine Ra (KIC) & $262 \pm 18$ & $363 \pm 26^{* \ddagger}$ & $243 \pm 13$ & $297 \pm 14^{* \ddagger}$ \\
Leucine Ra (Leu) & $184 \pm 13$ & $297 \pm 17^{* \ddagger}$ & & $216 \pm 11$ & $283 \pm 16^{* \ddagger}$ \\
Phenylalanine Ra & $88 \pm 5^{* \neq}$ & $194 \pm 5^{* \ddagger}$ & & $75 \pm 3$ & $83 \pm 3^{*}$ \\
Tyrosine Ra & $115 \pm 13^{\ddagger}$ & $102 \pm 8^{\ddagger}$ & & $69 \pm 5$ & $64 \pm 5^{\S}$ \\
& & & & \\
\hline
\end{tabular}

Leucine $\mathrm{Ra}$ is reported based on both the enrichment of KIC and leucine. ${ }^{*} P<0.001$ Basal vs. PN; ${ }^{\S} P<0.05$ Basal vs. PN; ${ }^{\ddagger} P<0.05$ EP vs. Term.

The concentrations of a number of amino acids were significantly different between the two groups. In general, when different, amino acid concentrations were higher in the EP group, more frequently in the PN period. In particular, tyrosine concentrations were 2.5-fold greater in EP compared with term newborns in both the basal and PN periods.

Isotopic plateau. Isotopic steady state was achieved for $\left[1-{ }^{13} \mathrm{C}\right] \mathrm{KIC},\left[\mathrm{d}_{5}\right]$ phenylalanine, $\left[\mathrm{d}_{4}\right]$ tyrosine, and $\left[\mathrm{d}_{2}\right]$ tyrosine, during both periods and in both groups as illustrated by Fig. 1 . Isotopic steady state was also achieved for $\left[1-{ }^{13} \mathrm{C}\right]$ leucine in both conditions and in both groups (not shown). The coeffi-
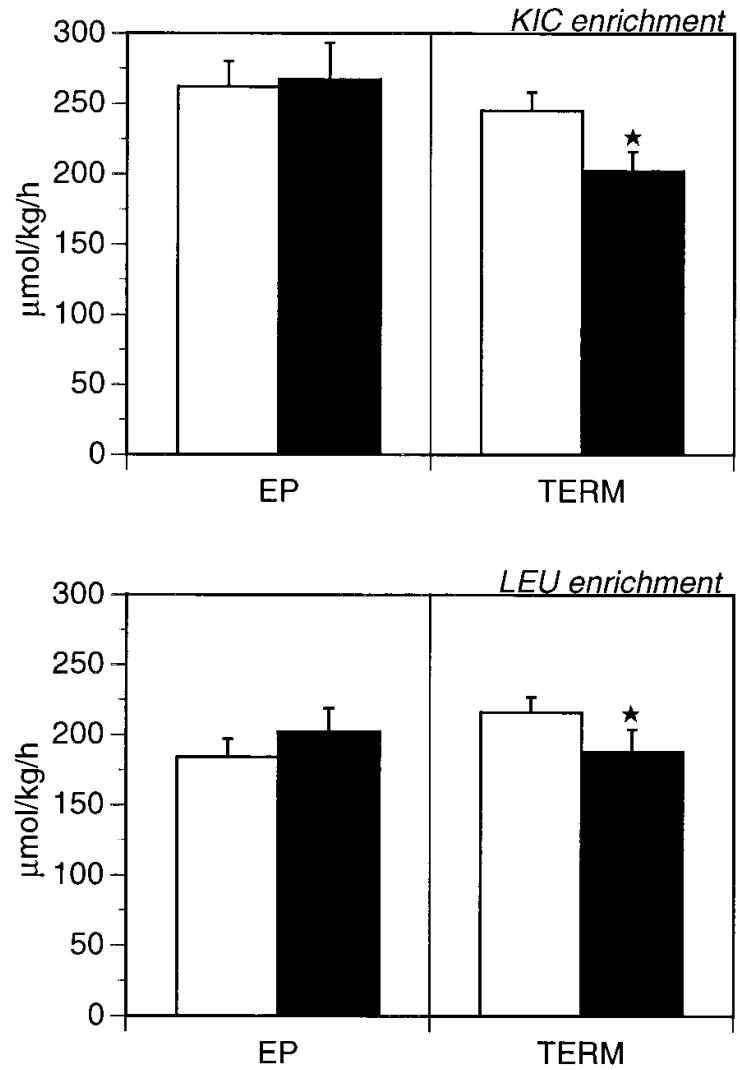

Figure 2. Endogenous leucine Ra in the basal period (open bars) and during PN (filled bars) in EP and term infants. Results are presented based on the enrichments of KIC and leucine. ${ }^{\star} P<0.01$ basal vs. PN. Endogenous leucine Ra (KIC) during PN is significantly higher in EP compared with term infants (ANOVA; $P<0.05$ ). 


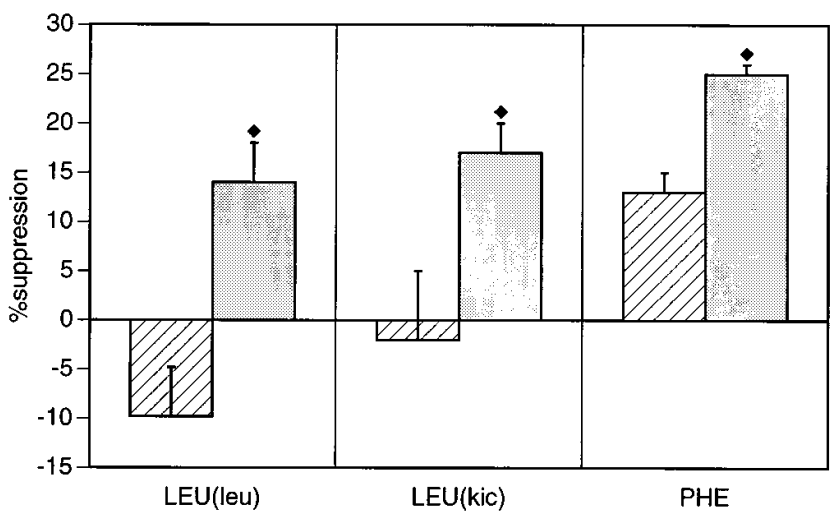

Figure 3. Percent suppression of endogenous leucine and phenylalanine Ra by PN in EP (hatched bars) and term (shaded bars) newborns. Endogenous leucine $\mathrm{Ra}$ is presented based on both leucine and KIC enrichments. $\bullet P<0.01 \mathrm{EP}$ vs. term.

cient of variation at plateau for $\left[1-{ }^{13} \mathrm{C}\right]$ leucine enrichment was $6 \%$ or less for both periods in both groups.

Leucine kinetics. The Ra of leucine determined during the studies are shown in Table IV; leucine Ra is presented based on both the enrichment of plasma leucine and the enrichment of plasma KIC. As expected, leucine Ra increased significantly in both groups during PN regardless of which precursor enrichment was used for calculation.

Endogenous leucine $\mathrm{Ra}$ (reflecting proteolysis) in the basal period and in response to PN is shown in Fig. 2. The results are again presented based on both KIC and leucine enrichment. In EP infants, endogenous leucine Ra did not significantly change from basal values in response to $\mathrm{PN}$ using either precursor enrichment (in $\mu \mathrm{mol} / \mathrm{kg} / \mathrm{h}$ : KIC enrichment basal $262 \pm 18$, PN 267 \pm 26 ; LEU enrichment basal 184 \pm 13 , PN 202 \pm 17 ). In contrast, endogenous leucine $\mathrm{Ra}$ significantly decreased from basal values in term infants as calculated by either KIC or leucine enrichment (in $\mu \mathrm{mol} / \mathrm{kg} / \mathrm{h}$ : KIC enrichment basal $243 \pm 13$, PN 202 $\pm 14 ;$ LEU enrichment basal 216 $\pm 11, \mathrm{PN} 187 \pm 16)$. The degree of suppression of endogenous leucine $\mathrm{Ra}$ by $\mathrm{PN}$ is shown in Fig. 3. Regardless of which precursor was used, endogenous leucine Ra was suppressed $\sim 15 \%$ in term infants whereas there was no significant suppression in EP infants during PN.

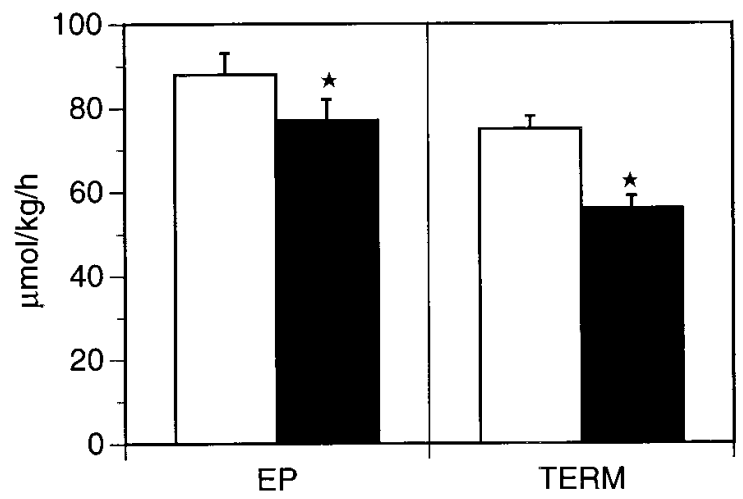

Figure 4. Endogenous phenylalanine release in the basal period (open bars) and during PN (filled bars) in EP and term newborns. ${ }^{\star} P$ $<0.001$ basal vs. PN. Endogenous phenylalanine release is significantly higher in EP compared with term infants in both the basal and PN periods (ANOVA; $P<0.05$ ).

Phenylalanine and tyrosine kinetics. Phenylalanine $\mathrm{Ra}$ is shown in Table IV. Similar to the changes in leucine Ra, there was a significant increase in phenylalanine $\mathrm{Ra}$ during $\mathrm{PN}$ in both groups. In addition, phenylalanine $\mathrm{Ra}$ was significantly greater in EP infants compared with term newborns in both the basal and $\mathrm{PN}$ periods.

Endogenous phenylalanine Ra (reflecting proteolysis) is shown in Fig. 4. During PN, endogenous phenylalanine Ra was significantly suppressed from basal values in both EP (basal $88 \pm 5, \mathrm{PN} 77 \pm 5 \mu \mathrm{mol} / \mathrm{kg} / \mathrm{h}$ ) and term infants (basal $75 \pm 3$, PN $56 \pm 3 \mu \mathrm{mol} / \mathrm{kg} / \mathrm{h}$ ). However, the degree of suppression was significantly greater in term infants (Fig. 3); term infants suppressed endogenous phenylalanine $\mathrm{Ra} 25 \%$ compared with $13 \%$ observed in EP infants. The degree of suppression based on phenylalanine kinetics was significantly greater $(P<0.05)$ than that based on leucine kinetics (regardless of enrichment precursor) for both EP and term infants.

Fig. 5 shows phenylalanine used for protein synthesis in the basal period and in response to PN in both groups. During PN, phenylalanine used for protein synthesis increased significantly in both EP (basal 71 $\pm 4 ; \mathrm{PN} 82 \pm 4 \mu \mathrm{mol} / \mathrm{kg} / \mathrm{h}$ ) and term infants (basal 63 $\pm 2 ; \mathrm{PN} 71 \pm 2 \mu \mathrm{mol} / \mathrm{kg} / \mathrm{h}$ ). The magnitude of this increase $(\sim 15 \%)$ was similar for both groups.

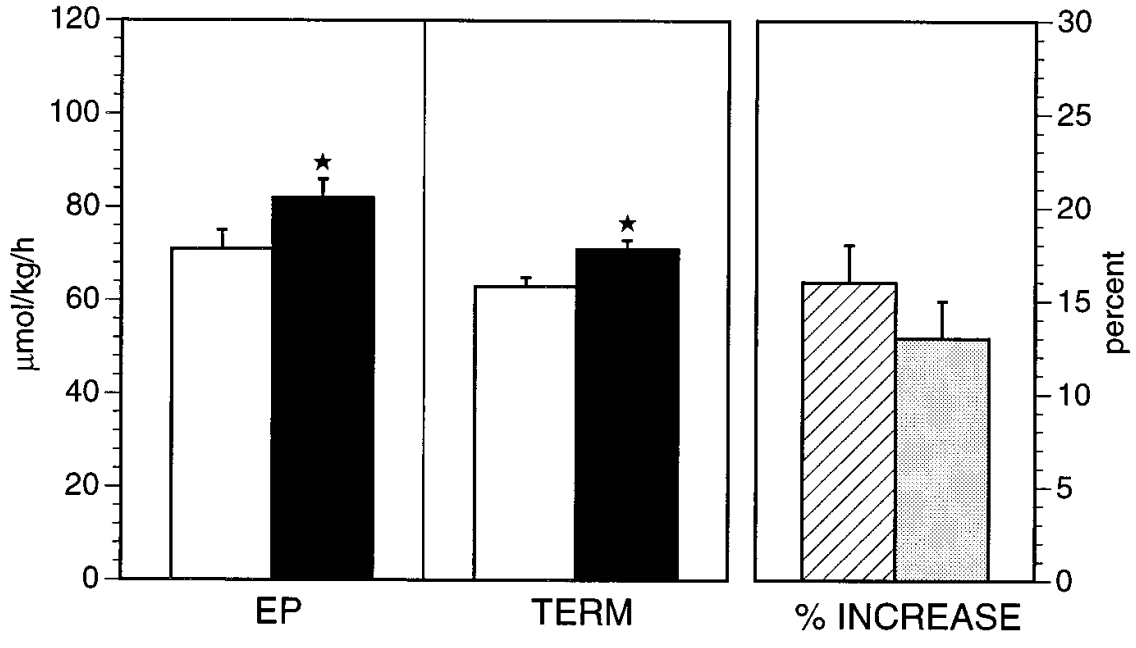

Figure 5. Phenylalanine utilization for protein synthesis in the basal period (open bars) and during PN (filled bars) in EP (hatched bar) and term (shaded bar) newborns. ${ }^{\star} P<$ 0.001 basal vs. PN. Phenylalanine utilization for protein synthesis is significantly higher in EP compared with term infants in the PN period (ANOVA; $P<0.05$ ). 


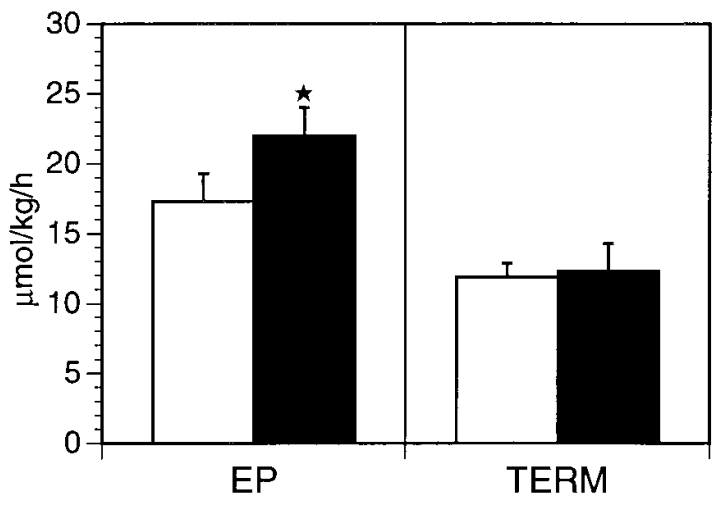

Figure 6. Phenylalanine hydroxylation rate in the basal state (open bars) and during PN (filled bars). ${ }^{\star} P<0.001$ basal vs. PN. Phenylalanine hydroxylation is significantly higher in EP compared with term infants in both the basal and PN periods (ANOVA; $P<0.05$ ).

The rate of phenylalanine hydroxylation to tyrosine is illustrated in Fig. 6. During PN, phenylalanine hydroxylation increased significantly in EP (basal $17 \pm 2 ; \mathrm{PN} 22 \pm 2 \mu \mathrm{mol} / \mathrm{kg} / \mathrm{h}$ ) but not term newborns (basal 12 \pm 1 ; PN $12 \pm 2 \mu \mathrm{mol} / \mathrm{kg} / \mathrm{h}$ ). In addition, the rate of phenylalanine hydroxylation was significantly higher in EP compared with term infants in both the basal $(P<0.05)$ and $\mathrm{PN}$ periods $(P<0.01)$.

The relationship between phenylalanine $\mathrm{Ra}$ and phenylalanine hydroxylation is shown in Fig. $7\left(y=0.337 x-13.7, r^{2}=\right.$ $0.63, P<0.001)$. This relationship remains significant $(P<$ 0.01 ) even if the two groups are considered separately. A similar but weaker relationship was also observed between phenylalanine concentration and phenylalanine hydroxylation $\left(y=0.08 x+7.6, r^{2}=0.26, P<0.01\right)$.

Tyrosine $\mathrm{Ra}$ is shown in Table IV. In response to PN, tyrosine $\mathrm{Ra}$ was unchanged in EP infants but was significantly reduced in term infants. Tyrosine $\mathrm{Ra}$ was significantly higher in EP compared with term newborns in both the basal and PN

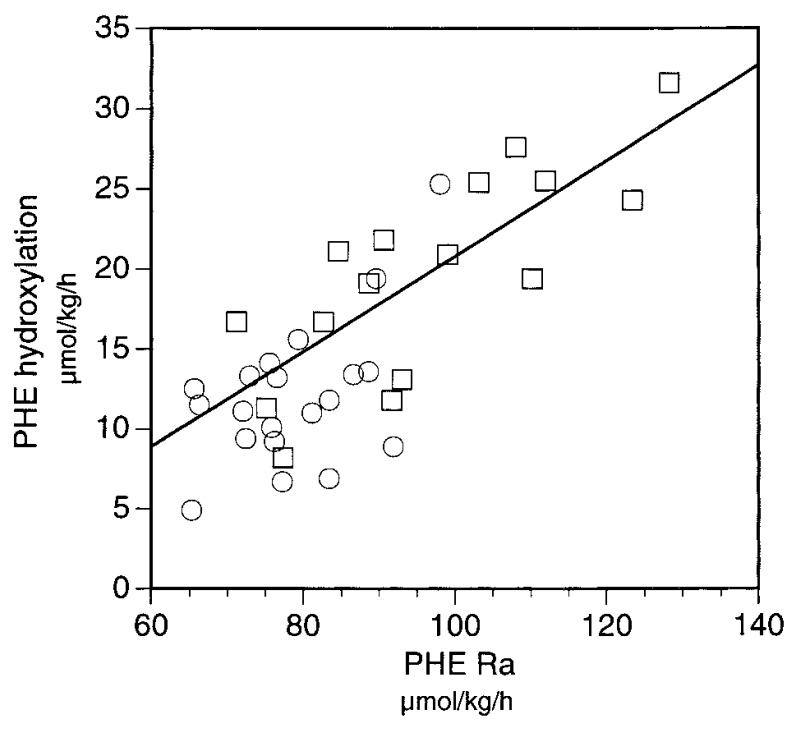

Figure 7. Relationship between phenylalanine hydroxylation and phenylalanine Ra. Boxes, EP; circles, Term.

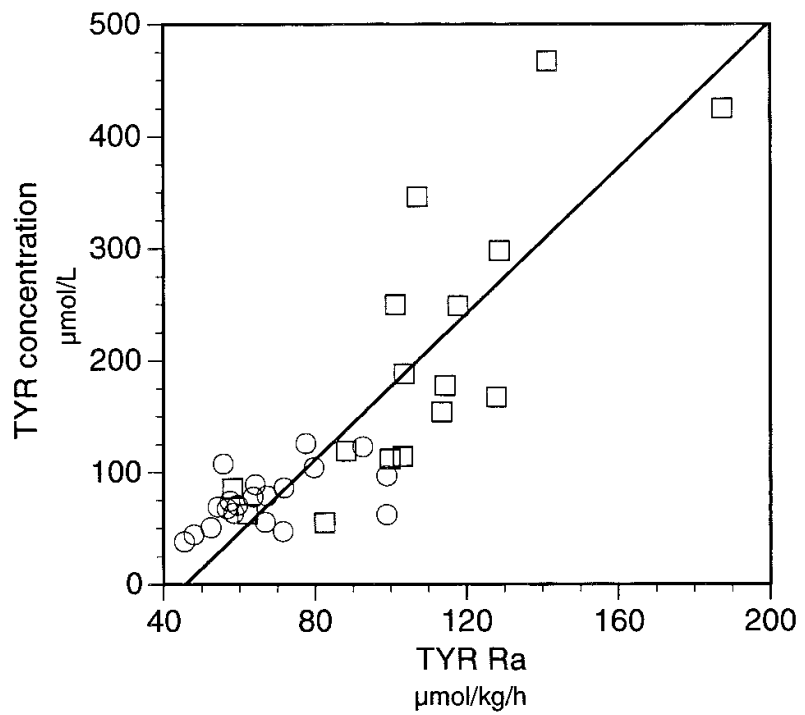

Figure 8 . Relationship between tyrosine concentration and tyrosine Ra. Boxes, EP; circles, Term.

periods. In both EP and term infants, phenylalanine hydroxylation made an important contribution to overall tyrosine $\mathrm{Ra}$ in the basal state (EP $15 \pm 1 \%$; term $17 \pm 1 \%$ ); this contribution significantly increased $(P<0.05)$ during $\mathrm{PN}$ in both groups (EP $21 \pm 1 \%$; term $19 \pm 1 \%$ ). The relationship between tyrosine $\mathrm{Ra}$ and tyrosine concentration is shown in Fig. $8(y=2.84 x-$ $\left.110, r^{2}=0.70, P<0.001\right)$; the relationship remains significant $(P<0.01)$ if EP and term infants are analyzed separately.

\section{Discussion}

In this study, we have evaluated how parenteral nutrition alters protein kinetics and phenylalanine hydroxylation in extremely premature and normal full term newborns. The data demonstrate that proteolysis is suppressed much less by parenteral nutrition in extremely premature compared with term newborns. In contrast, both groups of infants increased protein synthesis by a similar magnitude in response to parenteral nutrition. In addition, both extremely premature and normal term newborns actively hydroxylated phenylalanine to tyrosine. Furthermore, there appears to be no immaturity in this metabolic pathway as evidenced by higher rates of phenylalanine hydroxylation in extremely premature compared with term infants, and the ability of extremely premature infants to increase phenylalanine hydroxylation in response to parenteral nutrition.

Although protein kinetics and its regulation have been the subject of many studies in adults, there is rather limited information available in neonates. The neonates of the present study represent the extremes of viable human development in early postnatal life. We have previously examined these extremes of neonatal immaturity with respect to the ability of intravenous glucose to suppress proteolysis and glucose production $(4,9)$. In this regard, extremely premature and normal term newborns are remarkably similar; both groups nearly completely suppress glucose production during intravenous glucose administration at moderate levels of glycemia and low insulin concentrations, and in neither group does intravenous 
glucose result in the suppression of proteolysis, despite threefold increases in insulin concentration. However, it seems likely that such similarities between these two groups at very different stages of maturity might not persist in response to a more complete nutrient solution. To assess the effect of neonatal immaturity on the response to intravenous nutrition, we attempted to match the conditions under which each of the groups were studied as closely as possible. The basal period was designed to result in similar concentrations of glucose and insulin in both groups. Similar concentrations were in fact achieved, although the small $(\sim 2 \mu \mathrm{U} / \mathrm{ml})$ difference in insulin concentrations between the two groups in the basal state was statistically significant. We have determined previously that changes in insulin concentration of this magnitude have no significant effect on proteolysis in either extremely premature or term newborns $(4,9)$. Thus, the basal period is likely to be comparable in extremely premature and term infants, at least with respect to proteolysis. To gauge the response to nutrition, intravenous substrate was provided to both groups at identical rates and in sufficient quantities to support growth $(22,23)$. To minimize the effect of illness, the most clinically stable individuals in both groups were studied, extremely premature infants with minimal or no lung disease and no evidence of infection, and normal healthy full term infants. To control for the effect of age, both extremely premature and term infants were studied at the same postnatal age. Although it is difficult to exclude the influence of all factors other than immaturity, it would seem that immaturity is the predominant factor contributing to any differences between the two groups.

Accurately assessing proteolysis is an inherently difficult issue, and the assumptions and limitations involved in modeling proteolysis have been extensively discussed (24), including problems which sometimes occur during unlabeled amino acid infusions $(25,26)$. Therefore, to provide a more confident estimate of proteolysis, we traced the rates of appearance of two essential amino acids, leucine and phenylalanine. In addition, we also measured the enrichment of KIC, which is likely to reflect the intracellular enrichment of leucine, thereby providing a more accurate assessment of whole body proteolysis (17). The fact that each of these three determinations resulted in the same conclusion, namely that in response to parenteral nutrition, extremely premature infants suppress proteolysis to a lesser degree than term infants, lends credibility to the findings.

One particular issue relevant to all tracer amino acid studies is the potential for isotope recycling. Although some isotope recycling undoubtedly occurred in this study, we believe it did not significantly bias the results for the following reasons. First, in previous studies of both term and extremely premature infants receiving intravenous glucose, a recycling effect was not detected during a 4-5-h isotope infusion, as reflected by no significant change in enrichment over this period $(4,9)$. Second, in this study, the magnitude of isotope recycling is likely to be minimized by the exogenous infusion of amino acids ( $\sim 30 \%$ of flux) during the parenteral nutrition period; this is supported by the study of Melville et al. in which isotope recycling was unable to be detected during the fed state (27). Based on these considerations, it seems unlikely that the changes in proteolysis observed in response to parenteral nutrition were substantially influenced by isotope recycling.

We must note that although the leucine and phenylalanine tracers produced consistent qualitative results, the degrees of suppression of proteolysis based on these two tracers were dif- ferent. In both extremely premature and term newborns, the suppression of proteolysis based on phenylalanine was greater than that based on leucine, using either leucine or KIC enrichments to calculate leucine rate of appearance. Indeed, using either model of leucine kinetics, extremely premature infants exhibited no significant suppression of proteolysis in response to parenteral nutrition. This discrepancy between leucine and phenylalanine tracers is not unique to studies of newborns; these two tracers have produced differing degrees of suppression of proteolysis in adult studies evaluating the effects of enteral feeding and high-dose insulin infusions in normal subjects $(8,28,29)$, and moderate dose insulin infusions in patients with cirrhosis (30). Interestingly, however, in all of these adult studies the leucine tracer yielded a higher degree of suppression than the phenylalanine tracer $(8,28-30)$, opposite of what was observed in newborns. The reasons for phenylalanine and leucine kinetics yielding differing magnitudes of suppression are not clear in either adults or newborns; one possibility is that proteolysis is affected differently in proteins of differing leucine and phenylalanine content. However, the basic conclusions of the present study regarding the relative differences between extremely premature and term infants are unlikely to be altered by the precise resolution of this issue.

The findings of this study are consistent with the concept that extremely premature infants are resistant to the suppression of whole body proteolysis. While the precise reasons for this resistance are not clear, a number of possibilities exist. First, differences in body composition between extremely premature and term infants may play a role. Although the relative contribution of most organs to body weight is rather similar in extremely premature and term newborns, the protein composition of specific tissues is different (31), possibly with different sensitivities to the antiproteolytic effects of intravenous nutrition. Alternatively, extremely premature infants may be much more sensitive to small imbalances in the intravenous nutrition solutions. For example, neither cysteine nor tyrosine is present in significant amounts in the amino acid solution used in this study; a more balanced mixture of amino acids may be required to effectively reduce proteolysis in extremely premature infants. Finally, it is possible that high rates of proteolysis are a fundamental characteristic of immature individuals, providing a continuous source of amino acids for remodeling and growth $(1,2,4)$. In this case, all antiproteolytic mediators may be relatively ineffective in suppressing proteolysis in extremely immature newborns. Clearly, at this point, these issues remain to be resolved.

Although changes in proteolysis in response to parenteral nutrition in extremely premature and term newborns were different, the changes in protein synthesis were not. Protein synthesis increased significantly and by the same magnitude during parenteral nutrition in both groups. However, it must be noted that this estimate of protein synthesis is based solely on phenylalanine kinetics, unlike the multiple determinations used to assess proteolysis. Keeping this qualification in mind, the data are consistent with the notion that the ability to increase whole body protein synthesis in response to intravenous nutrition is relatively independent of the stage of development. Further support of this concept is provided by two previous studies in premature infants; these studies have also suggested that intravenous nutrition may result in increased protein synthesis as reflected by leucine kinetics $(32,33)$.

The capacity of premature infants to adequately convert 
phenylalanine to tyrosine via phenylalanine hydroxylase has long been questioned. Based on the classic amino acid elimination studies of Snyderman (34) tyrosine has been widely considered an essential amino acid in preterm infants (10-12). However, in studies carried out in human fetal liver, the activity of phenylalanine hydroxylase approached that of adults $(13,14)$. The results of the present study are consistent with the observations in fetal liver. Both extremely premature and normal newborns actively hydroxylate phenylalanine to tyrosine in the basal state. In fact, on a per kilogram basis, the basal rate of phenylalanine hydroxylation in normal newborns is approximately twice that of adults (20), and the basal rate of phenylalanine hydroxylation in extremely premature infants is $50 \%$ higher than in normal newborns. Thus, a significant portion of phenylalanine which appears in the circulation in the basal period is converted to tyrosine in both extremely premature and term newborns. Furthermore, in response to parenteral nutrition and phenylalanine administration, extremely premature infants actually increase the rate of conversion of phenylalanine to tyrosine. These data clearly demonstrate no developmental immaturity with respect to phenylalanine hydroxylation. Moreover, it is apparent that premature infants have the capacity to supply at least some of their endogenous tyrosine needs by metabolizing phenylalanine; thus in the strictest sense, tyrosine is not an essential amino acid in prematurity. However, it is not clear from our investigation or any other available data whether sufficient tyrosine is produced from phenylalanine in order to support optimal rates of protein accretion.

It is interesting to point out that although extremely premature infants significantly increased phenylalanine hydroxylation in response to parenteral nutrition and to phenylalanine delivery, normal newborns did not. The direct relationship between plasma phenylalanine rate of appearance and phenylalanine hydroxylation may provide a possible explanation for this apparent paradox (Fig. 7). This relationship suggests that the overall availability of phenylalanine may be an important factor in the hydroxylation rate $(35,36)$. In normal newborns who respond to parenteral nutrition with a large reduction in endogenous phenylalanine release, overall phenylalanine availability during parenteral nutrition is only slightly increased. On the other hand, extremely premature infants reduce endogenous phenylalanine release much less during parenteral nutrition, and therefore overall phenylalanine availability is substantially higher during intravenous nutrition.

To determine phenylalanine hydroxylation, we have also measured tyrosine rate of appearance; these data may provide some insight into a frequent abnormality of tyrosine metabolism in premature infants. Transient neonatal hypertyrosinemia is regarded as the most common abnormality of amino acid metabolism in humans (37), and can occur even independent of exogenous tyrosine intake. Indeed, even though significant amounts of tyrosine were not provided, the extremely premature infants in the present study had tyrosine concentrations two- to sixfold higher than normal infants during both the basal and parenteral nutrition periods. These high plasma tyrosine concentrations have been thought to be due to an immaturity in the enzyme responsible for tyrosine oxidation (37). Although this defect in tyrosine catabolism may play a role, the results of the present study would suggest that the tyrosine inflow into plasma may also be a significant factor. High concentrations of tyrosine observed in the extremely premature infants were accompanied by high tyrosine rates of appearance; in fact, there was a highly significant positive relationship between tyrosine concentration and tyrosine rate of appearance (Fig. 8). In view of these data, it is likely that transient neonatal tyrosinemia is not a simple defect in catabolism, although measurements of tyrosine oxidation in extremely premature infants will be required to precisely define the relative roles of tyrosine inflow and catabolism in this condition.

In summary, this study demonstrates that both extremely premature and term infants are capable of actively converting phenylalanine to tyrosine, and this conversion rate increases in response to parenteral nutrition in extremely premature newborns. This is clear evidence that there is no immaturity in the phenylalanine hydroxylation pathway. Both extremely premature and term infants respond to parenteral nutrition with similar significant increases in protein synthesis. In contrast, proteolysis is reduced to a far smaller degree by parenteral nutrition in extremely premature newborns. The factors responsible for this apparent resistance to the suppression of proteolysis in the very immature remain to be elucidated.

\section{Acknowledgments}

The authors wish to thank Katherine Lee for her technical assistance and Billie Crider for help in the preparation of this manuscript.

This work is supported in part by the National Institutes of Health (grants M-01RR750, P-60DK20542, R01 HD-29153), the James Whitcomb Riley Memorial Association, and by Bristol-Meyers Squibb, Inc.

\section{References}

1. Scornik, O. 1982. Protein synthesis and degradation during growth. Biochemical development of the fetus and neonate. In Biochemical Development of the Fetus and Neonate. L.T. Jones, editor. Elsevier Biomedical Press, New York. 866-894.

2. Goldspink, D., and F. Kelly. 1984. Protein turnover and growth in the whole body, liver and kidney of the rat from the foetus to senility. Biochem. J. 217:507-516.

3. Denne, S., and S. Kalhan. 1987. Leucine metabolism in human newborns. Am. J. Physiol. 253:E608-E615.

4. Hertz, D., C. Karn, Y. Liu, E. Liechty, and S. Denne. 1993. Intravenous glucose suppresses glucose production but not proteolysis in extremely premature newborns. J. Clin. Invest. 92:1752-1758.

5. Robert, J., D. Bier, X. Zhao, D. Matthews, and V. Young. 1987. Glucose and insulin effects on de novo amino acid synthesis in young men: studies with stable isotope labeled alanine, glycine, leucine and lysine. Metab. Clin. Exp. 31: 1210-1218.

6. Beaufrere, B., D. Chassard, C. Broussolle, J. Riou, and M. Beylot. 1992. Effects of D- $\beta$-hydroxybutyrate and long and medium-chain triglycerides on leucine metabolism in humans. Am. J. Physiol. 262:E268-E274.

7. Castellino, P., L. Luzi, D. Simonson, M. Haymond, and R. DeFronzo. 1987. Effect of insulin and plasma amino acid concentrations on leucine metabolism in man. J. Clin. Invest. 80:1784-1793.

8. Flakoll, P., M. Kulaylat, M. Frexes-Steed, H. Hourani, L. Brown, J. Hill, and N. Abumrad. 1989. Amino acids augment insulin's suppression of whole body proteolysis. Am. J. Physiol. 257:E839-E847.

9. Denne, S., C. Karn, J. Wang, and E. Liechty. 1995. Effect of intravenous glucose and lipid on glucose production and proteolysis in normal newborns. Am. J. Physiol. 269:E361-E367.

10. Heird, W., and S. Kashyap. 1992. Protein and amino acid requirements. In Fetal and Neonatal Physiology. Vol. I. R. Polin and W. Fox, editors. W.B. Saunders Co., Philadelphia. 450-462.

11. Uauy, R., H. Greene, and W. Heird. 1993. Conditionally essential nutrients. In Nutritional Needs of the Preterm Infant. R. Tsang, editor. Williams \& Wilkins, Baltimore. 267-280.

12. Rassin, D. 1994. Essential and non-essential amino acids in neonatal nutrition. In Protein Metabolism During Infancy. Vol. 33. N. Raiha, editor. Raven Press, New York. 183-192.

13. Taiha, N. 1973. Phenylalanine hydroxylase in human liver during development. Pediatr. Res. 7:1-4.

14. Jakubovic, A. 1971. Phenylalanine hydroxylating system in the human 
fetus at different developmental ages. Biochem. Biophys. Acta. 237:469-475.

15. Schwenk, W., P. Berg, B. Beaufrere, J. Miles, and M. Haymond. 1984. Use of t-butyldimethylisilylation in the gas chromatographic/mass spectrometric analysis of physiologic compounds found in plasma using electron-impact ionization. Anal. Biochem. 141:101-109.

16. Wolfe, R. 1992. Radioactive and Stable Isotope Tracers in Biomedicine: Principles and Practice of Kinetic Analysis. Wiley-Liss, Inc., New York. 471 pp.

17. Schwenk, W., B. Beaufrer, and M. Haymond. 1985. Use of reciprocal pool specific activities to model leucine metabolism in humans. Am. J. Physiol. 249:E646-E650.

18. Steele, R. 1959. Influence of glucose loading and of injected insulin on hepatic glucose output. Proc. NY Acad. Sci. 82:420-430.

19. Tserng, K., and S. Kalhan. 1983. Calculation of substrate turnover rate in stable isotope tracer studies. Am. J. Physiol. 245:E308-E311.

20. Thompson, G., P. Pacy, H. Merritt, G. Ford, M. Read, K. Cheng, and D. Halliday. 1989. Rapid measurement of whole body and forearm protein turnover using a [2H5] phenylalanine model. Am. J. Physiol. 256:E631-E639.

21. Nair, K., G. Ford, K. Ekberg, E. Fernqvist-Forbes, and J. Wahren. 1995. Protein dynamics in whole body and in splanchnic and leg tissues in type I diabetic patients. J. Clin. Invest. 95:2926-2937.

22. Pereira, G. 1995. Nutritional care of the extremely premature infant. Clin. Perinatol. 22:61-75.

23. Heird, W., and M. Gomez. 1992. Parenteral nutrition. In Nutritional Needs of the Preterm Infant. R. Tsang, editor. Williams \& Wilkins, Philadelphia. 225-242.

24. Bier, D. 1989. Intrinsically difficult problems: the kinetics of body proteins and amino acids in man. Diabetes Metab. Rev. 5:111-132.

25. Louard, R., E. Barrett, and R. Gelfand. 1990. Effect of infused branched-chain amino acids on muscle and whole-body amino acid metabolism in man. Clin. Sci. 79:457-466.

26. Nair, K., D. Matthews, S. Welle, and T. Braiman. 1992. Effect of leucine on amino acid and glucose metabolism in humans. Metab. Clin. Exp. 41:643648.

27. Melville, S., M. McNurlan, K. McHardy, J. Broom, E. Milne, A. Calder, and P. Garlick. 1989. The role of degradation in the acute control of protein balance in adult man: failure of feeding to stimulate protein synthesis as assessed by L $\left[1-{ }^{13} \mathrm{C}\right]$ leucine infusion. Metab. Clin. Exp. 38:248-255.

28. Biolo, G., P. Tessari, and S. Inchiostro. 1992. Leucine and phenylalanine kinetics during mixed meal ingestion: a multiple tracer approach. Am. J. Physiol. 262:E455-E463.

29. Denne, S., E. Liechty, Y. Liu, G. Brechtel, and A. Baron. 1991. Proteolysis in skeletal muscle and whole body in response to euglycemic hyperinsulinemia in normal adults. Am. J. Physiol. 261:E809-E814.

30. Tessari, P., G. Biolo, S. Inchiostro, R. Orlando, M. Vettore, and G. Sergi. 1993. Leucine and phenylalanine kinetics in compensated liver cirrhosis: effects of insulin. Gastroenterology. 104:1712-1721.

31. Widdowson, E. 1968. Growth and composition of the fetus and newborn. In Biology of Gestation. II. The Fetus and Neonate. N. Assali, editor. Academic Press, New York. 1-49.

32. Rivera, A., E. Bell, and D. Bier. 1993. Effect of intravenous amino acids on protein metabolism of preterm infants during the first three days of life. $\mathrm{Pe}$ diatr. Res. 33:106-111.

33. Mitton, S., A. Calder, and P. Garlick. 1991. Protein turnover rates in sick, premature neonates during the first few days of life. Pediatr. Res. 30:418 422

34. Snyderman, S. 1971. The protein and amino acid requirements of premature infants. In Nutricia Symposium: Metabolic Processes in the Fetus and Newborn Infant. H. Visser and J. Toreistra, editors. Stenfert Kroese, Leiden, Netherlands. $128-141$.

35. Shiman, R., S. Jones, and D. Gray. 1990. Mechanism of phenylalanine regulation of phenylalanine hydroxylase. J. Biol. Chem. 265:11633-11642.

36. Moldawer, L., I. Kawamura, B. Bistrian, and G. Blackburn. 1983. The contribution of phenylalanine to tyrosine metabolism in vivo. Biochem. J. 210: 811-817.

37. Mitchell, G., M. Lambert, and R. Tanguay. 1995. Hypertyrosinemia. In The Metabolic and Molecular Bases of Inherited Disease. Vol. 1. C. Scriver, A. Beaudet, W. Sly, and D. Valle, editors. McGraw-Hill, Inc., New York. 10771086. 